\title{
Why mandatory vaccination for healthcare workers should not be scrapped
}

\author{
Daniel Sokol medical ethicist and clinical negligence barrister
}

At the time of writing (24 January 2022), unvaccinated NHS workers in England have only until 3 February 2022 to get their first dose of the covid-19 vaccine. Those who do not risk dismissal.

The i newspaper reported last Friday that the government was now "actively" considering a temporary suspension of the policy. ${ }^{1} \mathrm{~A}$ few days before, a leaked document written by officials at the Department of Health and Social Care raised doubts on the wisdom of mandatory covid vaccines for NHS workers. ${ }^{2}$ The argument is that two vaccine doses provide only up to $32 \%$ effectiveness against omicron infection, then gradually wane until no longer effective without a booster. Further, omicron, although far more transmissible, is less likely to lead to severe illness and hospital admission than the delta variant.

If these facts are correct, then in my view the answer is not to abolish mandatory vaccination for NHS workers, but to add a requirement to have a booster, which gives a high degree of protection against omicron. ${ }^{3}$

The risk of hospital admission from omicron may only be half that of delta but it can still cause severe disease, even death, in some people, particularly older populations, the immuno-compromised, and those with underlying health conditions. ${ }^{45}$ While covid cases are starting to fall in the UK, on Tuesday 18 January 2022, there were 438 new covid deaths, the highest number since February last year. ${ }^{6}$ Omicron is still causing significant strain on the healthcare system.

The General Medical Council, in its guidance Good Medical Practice, instructs doctors to be "immunised against common serious communicable diseases (unless otherwise contraindicated)."7 The Royal College of Nursing announced on 22 September 2021 that all members of the nursing team should have "any vaccine deemed necessary to help protect themselves, patients, colleagues, family members, and the wider community" and noted that this requirement was enshrined in the code of the Nursing and Midwifery Council. ${ }^{8}$ The Hippocratic Oath, probably the best known ethical code for doctors, states "I will use treatments for the benefit of the ill in accordance with my ability and my judgement but from what is to their harm or injustice I will keep them."

In my view, being vaccinated against covid forms part of this Hippocratic obligation to keep the ill from harm. The unvaccinated may cause direct harm by transmitting the virus to their patients, although the jury is still out on the impact of vaccination on the transmissibility of covid. The latest covid-19 vaccine surveillance report from the UK Health Security Agency, dated 20 January 2022, noted that "several studies have provided evidence that vaccines are effective at preventing infection" and that "the vaccines provide some protection against transmission.” The report referred to a number of studies providing evidence of reduced risk of household transmission from vaccinated cases compared to unvaccinated ones. ${ }^{9}$

Unvaccinated healthcare workers can also cause indirect harm from staff absences and disruption to the health service caused by severe disease. The UK Health Security Agency's Technical Briefing 34, published on 14 January 2022, noted that vaccine effectiveness after a booster dose against hospital admission is $85-90 \%$ for the omicron variant. ${ }^{10} \mathrm{New}$ data from the Centers for Disease Control and Prevention show that unvaccinated adults aged 18 to 49 are 12 times more likely to be admitted to hospital than those who are vaccinated. For unvaccinated adults aged 50 to 64 , the likelihood of hospital admission is 44 times greater. ${ }^{11}$

Yet, despite acknowledging that clinicians who refuse vaccination are flouting professional guidance and failing to protect themselves and others, the Royal College of Physicians, the Royal College of General Practitioners, the Royal College of Nursing and the Royal College of Midwives are opposed to mandatory vaccination of healthcare workers due to the risk that it will exacerbate staff shortages, leaving some services untenable and therefore putting patients at risk. ${ }^{12-15}$ In my view, this is contrary to common sense and risks damaging the reputation of the medical professions.

The risk of reputational damage arises from the apparent incongruity of the profession's resistance to a law requiring its members to be vaccinated when it has shouted from the rooftops that everyone should get the vaccine and publicly declared that unvaccinated clinicians are in breach of their ethical code. "If it is so important," one might wonder, "why shouldn't it be mandatory for healthcare staff?"

Their position is also, I suspect, at odds with public opinion. A YouGov poll of 1,500 adults in the United States in July-August 2021 showed that $66 \%$ of respondents believed medical providers should be required to be vaccinated against covid-19. ${ }^{16}$ In France, $72 \%$ held that view in a poll last July for $L e$ Figaro. ${ }^{17}$ This has become official policy in many countries, including France, Germany, Italy, Greece, Finland, Croatia, the Czech Republic, Hungary, Lebanon, Poland and New Zealand. ${ }^{8}$

Some have called for a gentler approach towards vaccine hesitant staff, focused on discussion and 
education. This approach can be effective, but there has been plenty of time for that. NHS staff were one of the first to be offered the vaccine, over a year ago. Many NHS trusts have held Q\&A sessions and offered support for unvaccinated staff. Those who remain unpersuaded at this late stage, even when warned by their professional bodies that they are breaching their code of ethics, are unlikely to change their minds without a strong incentive to do so. This incentive is their continued employment in the NHS.

The greatest fear associated with mandatory vaccination is a mass exodus of staff, leaving the health system in disarray. There are approximately 73000 patient-facing NHS workers who have not received a single dose of the vaccine. ${ }^{19}$ In France, as of November 2021, only 1,350 clinicians out of 374 ooo have been banned from practising medicine for failing to comply with the law on mandatory vaccination. ${ }^{20}$ In New York state, which imposed mandatory vaccination for healthcare staff last September, the predicted staffing crisis in hospitals did not materialise. ${ }^{21}$

Healthcare workers, like everyone else, are free to refuse the covid vaccine. If they exercise this right, however, they cannot work with vulnerable patients. To do so would be contrary to the ethics of their profession, as set out in their professional codes, and is likely to damage public trust and confidence in the medical profession.

Competing interests: Daniel Sokol is a medical ethicist and clinical negligence barrister. He is the author of 'Tough Choices: Stories from the Front Line of Medical Ethics.' (Book Guild, 2018).

Provenance and peer review: not commissioned, not peer reviewed

1 The i. Covid vaccine mandate for NHS staff could be paused. https://inews.co.uk/news/politics/covid-vaccine-mandate-nhs-staff-paused-government-workers-sacked-1416578

2 The Guardian. Health department warnign over vaccine mandate for NHS England staff. https:/www.theguardian.com/society/2022/jan/18/health-department-warning-over-vaccinemandate-for-nhs-england-staff

3 Mahase E. Covid-19: Hospital admission 50-70\% less likely with omicron than delta, but transmission a major concern. BMJ2021;375:n3151. doi: 10.1136/bmj.n3151. pmid: 34952835

4 Hospitalization Risk from Omicron 'Around a Third of Delta' https://www.webmd.com/lung/news/20220105/hospitalization-omicron-delta

5 What we know about omicron symptoms recovery. https://www.beckershospitalreview.com/public-health/what-we-know-about-omicron-symptoms-recovery-a-clinical-timeline.html

6 Britain reports 438 new covid deaths, highest https://www.reuters.com/world/uk/britain-reports438-new-covid-19-deaths-highest-since-february-2022-01-18/

7 General Medical Council. Good Medical Practice. https://www.gmc-uk.org/ethical-guidance/ethicalguidance-for-doctors/good-medical-practice/domain-2--safety-and-quality

8 The Royal College of Nursing. RCN position on mandating vaccination for health and social care staff. https://www.rcn.org.uk/about-us/our-influencing-work/position-statements/rcn-positionon-mandating-vaccination-for-health-and-social-care-staff

9 Covid-19 vaccine surveillance report. https://assets.publishing.service.gov.uk/government/uploads/system/uploads/attachment_data/file/1049160/Vaccine-surveillance-report-week-32022.pdf

10 SARS-CoV-2 variants of concern and variants under investigation in England. https://assets.publishing.service.gov.uk/government/uploads/system/uploads/attachment_data/file/1048395/technical-briefing-34-14-january-2022.pdf

11 The Guardian. Unvaccinated seniors 49 times more likely to be hospitalized than those with boosters - CDC. https://www.theguardian.com/us-news/2022/jan/21/cdc-covid-vaccine-hospitalsamericans

12 RCP responds to news that COVID-19 vaccines will be mandatory for NHS frontline staff https://www.rcplondon.ac.uk/news/rcp-responds-news-covid-19-vaccines-will-be-mandatorynhs-frontline-staff-0

13 RCGP opposes mandatory Covid-19 vaccination for NHS workers https:/www.rcgp.org.uk/aboutus/news/2021/november/opposition-mandatory-vaccination-nhs-workers.aspx

14 RCN position on mandating vaccination for health and social care staff https://www.rcn.org.uk/about-us/our-influencing-work/position-statements/rcn-position-onmandating-vaccination-for-health-and-social-care-staff

15 RCM calls for immediate delay to NHS staff mandatory vaccination plans https://www.rcm.org.uk/media-releases/2021/december/rcm-calls-for-immediate-delay-to-nhsstaff-mandatory-vaccination-plans/

16 The Economist/YouGov Poll. July 31 - August 3, 2021 - 1500 U.S. Adult Citizens https://docs.cdn.yougov.com/8w7calyx30/econTabReport.pdf

17 Covid-19: 72\% des Français pour la vaccination obligatoire des soignantshttps://www.lefigaro.fr/politique/sondage-72-des-francais-pour-la-vaccination-obligatoire-des-soignants-20210701
18 Factbox: Countries making COVID-19 vaccines mandatory https://www.reuters.com/business/healthcare-pharmaceuticals/countries-making-covid-19-vaccines-mandatory-2021-08-16/

19 The I. Covid vaccine mandate for NHS staff could be 'paused' by Government over fears 70000 workers would be sacked https://inews.co.uk/news/politics/covid-vaccine-mandate-nhs-staffpaused-government-workers-sacked-1416578

20 Le Figaro. Obligation de vaccination: 160 médecins libéraux suspendus à ce jour, selon l'Assurance maladie https://www.lefigaro.fr/flash-actu/obligation-de-vaccination-160-medecins-liberauxsuspendus-a-ce-jour-selon-l-assurance-maladie-20211118

21 Dyer O. Covid-19: New York's health workers agree to vaccinate as mandate bites. BMJ 2021;374:n2390. doi: 10.1136/bmj.n2390. https://www.bmj.com/content/374/bmj.n2390. pmid: 34583927 